Portland State University

PDXScholar

\title{
Congestive Heart Failure Self-Management Among US Veterans: The Role of Personal and Professional Advocates
}

\author{
Eleni Skaperdas \\ Veterans Health Administration \\ Anaïs Tuepker \\ Oregon Health \& Science University \\ Christina Nicolaidis \\ Portland State University \\ Jessica K. Robb \\ Veterans Health Administration \\ Devan Kansagara \\ Veterans Health Administration
}

Follow this and additional works at: https://pdxscholar.library.pdx.edu/socwork_fac

IPraxtopalge fomadalitiodaMaadthorsocial Work Commons, Health Services Research Commons, and the Medicine and Health Commons

Let us know how access to this document benefits you.

\section{Citation Details}

Skaperdas, E., Tuepker, A., Nicolaidis, C., Robb, J. K., Kansagara, D., \& Hickam, D. H. (2014). Congestive heart failure self-management among US veterans: The role of personal and professional advocates. Patient education and counseling, 95(3), 371-377.

This Article is brought to you for free and open access. It has been accepted for inclusion in Social Work Faculty Publications and Presentations by an authorized administrator of PDXScholar. For more information, please contact pdxscholar@pdx.edu. 


\section{Authors}

Eleni Skaperdas, Anaïs Tuepker, Christina Nicolaidis, Jessica K. Robb, Devan Kansagara, and David H. Hickam 


\title{
Congestive heart failure self-management among US veterans: The role of personal and professional advocates
}

\author{
Eleni Skaperdas ${ }^{\text {a,* }}$, Anaïs Tuepker ${ }^{\mathrm{a}, \mathrm{b}}$, Christina Nicolaidis ${ }^{\mathrm{b}, \mathrm{c}, \mathrm{d}}$, Jessica K. Robb ${ }^{\mathrm{a}}$, \\ Devan Kansagara a,b, David H. Hickam ${ }^{\mathrm{a}, \mathrm{e}}$ \\ ${ }^{a}$ Portland VA Medical Center Health Services Research and Development, VISN 20 PACT Demonstration Laboratory, Veterans Health Administration, \\ Portland, USA \\ ${ }^{\mathrm{b}}$ Division of General Internal Medicine and Geriatrics, Department of Medicine, Oregon Health and Science University, Portland, USA \\ ' School of Social Work, Portland State University, Portland, USA \\ ${ }^{\mathrm{d}}$ Department of Public Health and Preventive Medicine, Oregon Health and Science University, Portland, USA \\ ${ }^{\text {e }}$ Patient Centered Outcomes Research Institute, Washington, USA
}

\section{A R T I C L E I N F O}

\section{Article history:}

Received 25 September 2013

Received in revised form 15 February 2014

Accepted 2 March 2014

\section{Keywords:}

Primary care redesign

Self-management

Qualitative research

Heart failure

Veterans

US

\begin{abstract}
A B S T R A C T
Objective: Understand patients' experiences with primary care services for congestive heart failure (CHF) and explore the relationship between health services and self-management.

Methods: We conducted semi-structured interviews with thirty-nine patients with CHF receiving care at one Veterans Affairs Medical Center (VA). We analyzed data using thematic content analysis.

Results: Participants acknowledged the importance of ongoing engagement in the plan of care for CHF. They attributed success in this effort to be greatly influenced by personal advocates. The advocates included both members of the healthcare team with whom they had a continuity relationship and friends or family members who assisted on a daily basis. Participants also identified psychological symptoms as a major barrier to carrying out self-care.

Conclusion: Patients identify relationships with health care workers, help from family and friends, and mental health problems as major influences on the ability to manage their CHF.

Practice implications: Efforts to optimize CHF self-management should attend to health system and psychosocial barriers to care.
\end{abstract}

Published by Elsevier Ireland Ltd.

\section{Introduction}

Congestive heart failure (CHF) is a chronic illness associated with substantial morbidity and mortality [1,2]. CHF treatment usually requires both medication management and lifestyle interventions that aim to reduce the frequency of exacerbations. It is widely accepted that self-management, a concept often defined as "patients' active participation in their own treatment", is of crucial importance for achieving better clinical outcomes [3,4]. Patients are expected to self-manage their illness by following potentially complex medication regimens, adhering to dietary restrictions, and vigilantly assessing symptom changes such as weight gain and shortness of breath.

\footnotetext{
* Corresponding author at: Portland VA Medical Center, Mailcode R\&D63, PO Box 1034, Portland, OR 97207, USA. Tel.: +1 503220 8262x56787; fax: +1 5032735367.

E-mail address: eleni.skaperdas@va.gov (E. Skaperdas).
}

A variety of clinical approaches have been developed in the United States and abroad to engage patients with CHF more effectively, including short targeted programs providing education and practical disease management training. These time-limited programs have shown a limited impact on both measures of selfcare and clinical outcomes such as hospitalizations and mortality [5-10]. An alternative approach is to promote systems that provide embedded and continuous self-management support within regular primary care clinic activities [11].

Efforts to improve care of patients with CHF in primary care clinics depend upon understanding patients' needs and crafting approaches that have the best chance of meeting those needs. An emerging literature qualitatively explores the realities and struggles of living with CHF [12]. Multiple studies document the emotional distress and difficulty that often accompany the diagnosis, progressive deterioration, and complex management of CHF [13,14]. However, less is known about patients' views of how healthcare providers encourage or inhibit self-management, particularly within an integrated healthcare system [15-17]. Our 
objective was to explore and understand how patients with $\mathrm{CHF}$ engage with health services and perform self-care, with the ultimate goal of using this information to guide patient-centered improvement of current clinical practices.

\section{Methods}

\subsection{Setting}

VA is the largest integrated care delivery network in the United States. VA offers subsidized care to a specific population: those who have served in the US military. This study was conducted in a large urban medical center, during the early stages of implementation of a patient-centered medical home (PCMH) model, known within VA as the Patient Aligned Care Team (PACT) initiative. This team-based model of care emphasizes increased access to care, efficiency, coordination, continuity, and expanded preventative services, especially for those with chronic illness [18]. Our Institutional Review Board approved this study.

\subsection{Recruitment and sampling}

We identified potential participants by searching the VA's electronic medical record system for patients with International Classification of Diseases, Ninth Revision diagnosis codes for CHF. To determine study eligibility, we conducted chart reviews; we excluded patients if they were not community dwelling, had a terminal illness, dementia, drug or alcohol abuse, a history of threatening behavior, major mental illness, were unable to give informed consent, or were not enrolled within VA primary care.

In the initial recruitment stage, we mailed 150 patients a letter describing the study and asking participants to return an opt-out form if they did not wish to receive a phone contact. Twenty declined contact, 44 contacted the research team indicating interest, and 86 did not respond. Our final sample consisted of 5 hospitalized patients who participated in pilot testing of the interview guide, 24 patients who opted in as a result of the recruitment letter, and 10 patients who did not initially respond to the letter but who agreed to participate when contacted in a follow-up phone call. To elicit experiences from patients with different levels of CHF severity, we purposely balanced our sample so that approximately half of the patients had been hospitalized for $\mathrm{CHF}$ in the past six months, ending recruitment when this balance was achieved and we had interviewed the majority of interested patients.

\subsection{Data collection}

A research assistant trained in qualitative interviewing techniques (such as open-ended response elicitation and reflective listening) conducted the interviews. All participants consented to have an audio recording of the interview. We used a semistructured interview guide with questions and follow-up probes that asked about patients' interactions with the healthcare system and their experiences with self-care (see Appendix A). The interviewer kept field notes of emotional reactions, interactions, and communications not captured by the digital recording. Participants were allowed to include their supporters during the interview, and 11 interviews were conducted with a supporter present. Supporters were wives, other family members, or a close friend. No questions were asked about the supporters' medical problems or other personal information, but the supporters were asked to provide written consent for having their comments recorded and transcribed. Interviews ranged from 25 to $90 \mathrm{~min}$, averaged $40 \mathrm{~min}$, and were recorded and transcribed verbatim.

\subsection{Data analysis}

We analyzed our data using the technique of thematic analysis [19], a method that accommodates diverse approaches to qualitative data and emphasizes transparency and thoughtfulness about underlying analytic choices. In this study, we used an inductive approach (consistent with grounded theory) in which themes are identified in the process of understanding the data, as opposed to a theoretical approach driven by predominant models or questions in the existing literature. We analyzed data at an explicit rather than latent level, focusing on what participants said, not the constructs or contextual factors that in theory shape what was said. Additionally, we chose to use an essentialist/realist paradigm that draws implications from participants' statements, rather than a constructionist approach that would have theorized about the contextual factors shaping, constraining, or enabling those statements.

The full research team, consisting of VA primary care providers, experienced qualitative researchers, and research assistants, reviewed a subset of transcripts to develop an initial codebook focused on emerging themes. Following techniques of conventional content analysis [20], the codebook was then iteratively refined as two trained research assistants coded texts, identified new themes, and combined overlapping categories using Atlas Ti (ATLAS.ti Scientific Software Development GmbH, Berlin, Germany). Differences in coding were discussed and reviewed with an experienced qualitative researcher, who facilitated consensus between the coders. The full research team then met to review and finalize themes.

We used a subjective heuristic to determine significance of themes and inclusion in this paper. A significant theme needed to: (1) be expressed by multiple participants; (2) be expressed as a central concern; and (3) relate to the research topics explored. In response to feedback from peer review, we made a final return to the coded data to clarify themes. Steps in our analytic process are shown in Fig. 1.

\section{Results}

\subsection{Participant characteristics}

Between May 2012 and December 2012 we interviewed 39 patients. Participants ranged in age from 53 to 89 years, with a mean age of $69(S D=8.8)$; two were female, two identified as African American, 28 as White, and nine declined to share information about race/ethnicity. Fifteen of the participants were currently married.

\subsection{Findings}

We identified four common themes describing how participants' experiences of living with and receiving care for $\mathrm{CHF}$ affected their ability to participate in self-management.

\subsubsection{Good care is personal and responsive}

Some patients described having their needs for care consistently met, and spoke enthusiastically of the care that they were receiving. Among these patients, a common refrain was that providers and/or other team members personally knew them and their health problems.

“. . . they're aware of my history when I go in [to my primary care clinic]...they call me by first name...The doctors really care, and I mean, they call me at home and they're. . . just on it. And, I just feel so much more comfortable that uh, I'm gonna be around for a long while, maybe [chuckles]. . .She'll talk to me for 


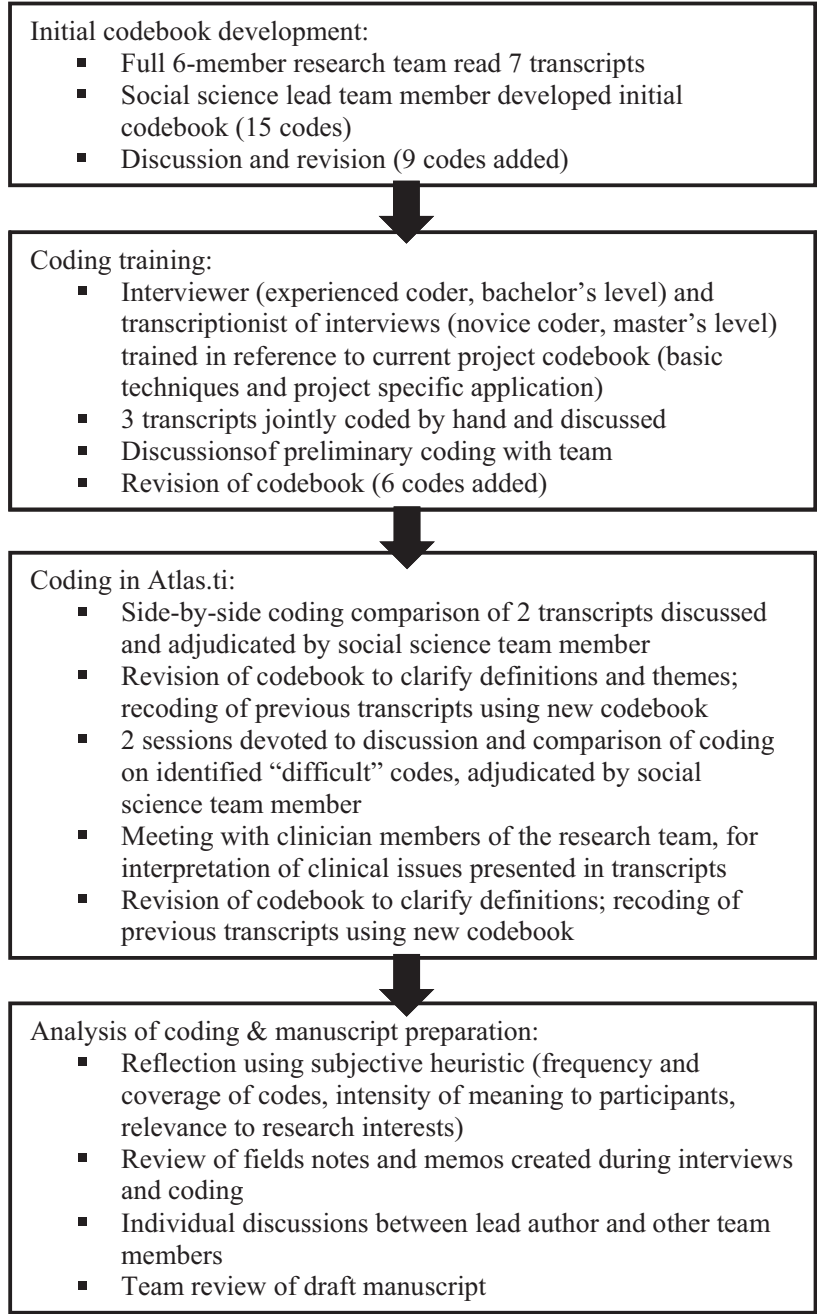

Fig. 1. Coding and analytic process.

ya know, whatever, 30 min or whatever I need to, ya know, till I understand what the hell's going on." (Patient 32)

Patients also described good care as responsive, where participants felt their own sense of urgency reflected in the actions of their care givers.

"I get appointments if I need them. If there's an emergency. . . he got me in, squeezed me in between people." (Patient 23)

In contrast, some patients felt that the VA system did not recognize their sense of urgency or concern. One patient who was intensely frustrated by difficulties getting an appointment with the cardiology clinic stated, "the heart is one organ you don't mess with," (Patient 5, female) suggesting this patient's perception of access to specialty heart care as critical. Yet for several patients, the lack of responsive, personal relationships with cardiology specialty care providers was cause for dissatisfaction and alarm:

“To be a cardiology patient now and know that I can't access cardiology, and I can't talk to anybody in cardiology, it makes me nervous, it makes me frightened." (Patient 5, female)

Participants also identified situations in which they had worsening CHF symptoms and were unable to get appointments or have telephone calls returned quickly. Such delays in communications sometimes caused them to seek care in the emergency department, described by one participant (14) as "hit the panic button." These patients and supporters felt they did not receive the elevated level of care that they needed at that point in time. However, delays in communication or access were not always perceived as a failure or a lack of recognition of the patient's concerns. The perceived responsiveness of the care team often seemed to be as important as the actual time until a response:

"If I. . . ask to have a prescription refilled, they say okay, and I usually, that's okay. I get the prescription in the mail, and it usually comes right away. And sometimes if I have a question, and they can't answer, I'll ask them the questions, and they'll say we'll talk to him [patient's primary care provider] and get back to you, or make a suggestion of what I should do...Oh, they've been real helpful." (Patient 17, female)

Patients sometimes explicitly described how a lack of personalized, responsive care limited their ability to participate in self-management. For example, one patient described how a provider who "listens, but doesn't hear" makes it hard for him to manage changes in his medication plan.

"I wish when we were talking he would be like, 'Okay, Mike (pseudonym), now tell me about this,' and not be doing all this other stuff that he has to do...So he wouldn't send me meds that I have to pay $\$ 24$ for a 3 month's supply that I don't take anymore." (Patient 35)

Within the context of a transition to team-based care, some patients described receiving the best guidance from members of their care team other than the primary care provider (PCP). For example, one patient described his relationship with both his PCP and the nurse on the team:

"[Interviewer: ... who mainly talks to you about your heart?] Patient: ...let me put it like this...My primary says she has quite a heavy caseload, so talking to her is like trying to direct congress. So I have her nurse, who she and I, her assistant, have a first name casual basis, so anything that I need, or feel I need, to ask the question about, or find out about, I go through Mary (pseudonym), and Mary is my intermediary, and so as far as communication with my primary, through other sources, I have it.... And Mary is working for two doctors too, so she's pretty tight. But she and I have a thing. [Interviewer: How do you usually get in touch with [her]? Patient:...[on the] telephone, and she's very good at getting back to me, if not the same day, or the next day... we work good along those lines of communication. So, no problem."

\subsubsection{Perceiving an "advocate" within the system improves patient experience}

Whether in specialty or primary care clinics, patients described staff members who acted as their advocates, or, in patients' own words, as "that person that goes out and raise[s] a flag for you," (Patient 33) a "port in the storm," (Patient 31) or "my beacon and my rock" (Patient 5, female). These personal advocates often lobbied for patient services outside of their scope of practice, offered informational support friends and family members could not offer, and (in some cases) made up for a perceived lack of personalized, caring attention from other staff. For example, one patient described how his primary care visits were "limited on time" (Patient 3) and consequently do not address all his needs. Regarding his mental health provider, however, Patient 3 mentioned that she helps with "...everything she can." His supporter clarified that the mental health provider often set them up with classes, or facilitated access to other specialty providers.

In contrast, some patients described a very negative experience, by one patient characterized as feeling that they "don't have anybody" (Patient 10). These patients experienced a lack of continuity of providers in managing $\mathrm{CHF}$ as detrimental to their 
health. They did not know who to contact when CHF symptoms escalated, and were worried and uncertain about their heartrelated prognosis:

"I keep on getting new doctors. I'm kind of falling through the cracks because of this. ... I got a new doctor, Dr. [Name]. She got my blood pressure back to normal, and then she left. And I didn't get any word from anybody for a long time. My blood pressure slowly started coming back up again and PVC's are comin' back up again. Then I got another doctor. Now I got a new doctor. . . [I saw] the doctor between my regular doctors and he said 'I don't really want to treat you because you're not really my patient. I don't want you.' Like that. And I go, 'Well, okay, I'll see you in a year.'... [Providers should] have a meeting and explain to [patients with CHF] what's happening - you know, 'how is my heart' Nobody told me. I don't know what's wrong with me. I'm breaking down here [Patient is crying]." (Patient 6)

\subsubsection{Self-management is not an individual activity}

Patients frequently described receiving tremendous help from a supporter. When faced with functional barriers, a lack of motivation, or mental illness, supporters often self-managed on the patient's behalf. Patients often described supporters' assistance as central rather than peripheral. Certain activities, such as medication management and observance of a low-salt diet, were often reported as the exclusive responsibility of (or enforced by) a supporter.

“I don't [keep track of my medications] . . My brother does. I got tired of it. Saying, 'did you take your medication today,' and I said, 'I don't remember.... If you want to know if I took my medication, you give them to me.' So, he started giving them to me...he calls the order in for me, to make sure I got a full prescription, and he takes care of all of that for me... he hands me a pill cup, I look in to see that there are pills in it, I take the pills." (Patient 16)

Supporters frequently acted as a liaison between the patient and the healthcare system. Many patients mentioned that supporters scheduled and attended appointments with the patient and called their care teams with questions about heart failure symptoms and medications. Patient 7 responded to many interview questions with "I don't know;" then remarked during the interview closing:

“...If my wife was here she'd probably have stuff to tell you. . .that's one of the things about that doctor that we had for a bunch of years here. . she'd come with me, and he'd ask me a question and I'd say well, I don't know, and then she'd sure chime in and tell them what they wanted... Then when she quit going. . . he asked me, ' . . where's your wife?' and I told him that she wasn't feeling good so she didn't come with me. 'Oh' he says, "How am I going to find out anything?"

Patients expressed appreciation when providers made an effort to include supporters in the patient's care. Patient 22 stressed that providers "took the time to talk to her [his wife/supporter] too" when positively reflecting on his care during a recent hospitalization for CHF. A few patients also mentioned times when supporters had been excluded or their presence had not been prioritized. One patient (31) described a negative reaction to a PCP who had refused to speak with his wife on the phone about a personal matter.

3.2.4. Mental health concerns compete with CHF as a priority for selfcare

Though our interview guide did not include questions related to mental health, many patients spontaneously discussed mental health issues. Psychological symptoms often made it difficult for participants to manage $\mathrm{CHF}$ and take advantage of system resources. For some, addressing their mental health challenges was a higher priority than managing their CHF. For example, when discussing his provider's recommendation to quit smoking, this participant explained:

"But I'm in a battle for my life mentally right now...And the smoking thing is the one thing that is keeping me alive. I mean, I've got the mental health going on, I've got my physical health going on.... And the more I worry, the more chest pains I get. I do know that. And I'm constantly worrying. I'm constantly angry. I get up angry, I go to bed angry." (Patient 10)

This interaction between physical and mental health was reflected in the comments of several participants, like one patient who commented that, "...everything is related to PTSD. I've discovered that” (Patient 20). Many participants also discussed how CHF itself negatively affected mental well-being; the most frequently mentioned difficulty was coping with the loss of an active lifestyle. A number of patients made comments about how CHF had left them unable to "do the things I once could" (Patient 30) or with "less and less abilities to do things that I want to do" (Patient 11). This in turn led to a feeling of hopelessness that was a barrier to self-management.

"...the insidious thing is that the disease may very well have contributed to the heart problem, and the heart problem for sure contributes to my inability to do what I've always done my whole life long, to keep fit and keep my weight down. ..things that I used to do, loved to do, I can't do, and I'm looking at probably not being able to do the rest of my life. I tend to put on weight. . I'm pushing 300 now and that's horrible, horrible. I'm ashamed of myself. But then nothing I can do seems to work, because all the things that have worked I can't do anymore. .. So it's frustrating, it is.... [It] attacks your state of mind in some ways." (Patient 34)

Very few of these patients, however, described sharing these experiences with their care teams, or learning how to address these feelings as part of their self-management.

\section{Discussion and conclusion}

\subsection{Discussion}

CHF is a serious medical problem that requires ongoing adherence to complex treatment regimens. Although researchers implicate access to care and strength of the patient-provider relationship as obstacles to $\mathrm{CHF}$ management, few have explored and clarified how the healthcare system enables or inhibits selfcare $[13,15,17]$. This series of in-depth patient interviews, conducted relatively early in the implementation of a $\mathrm{PCMH}$ model of care, highlights the centrality of the patient-provider relationship, as well as the role of family members or other supporters in patients' perceptions about overall quality of care and their ability to participate effectively in that care. The findings indicate that careful attention to the milieu and support system of individual patients can permit better tailoring of treatment plans and strategies.

While many participants reported satisfaction with their care, a significant minority described how feelings of being lost in the system, negative patient-provider relationships, and the absence of a perceived advocate affected their motivation and practical ability to self-manage. A few qualitative studies have hinted at, but not fully explored, the complexities of the patient-provider relationship in a CHF population $[21,22]$. One mixed-methods analysis found that more than $30 \%$ of CHF patients report conflict with their healthcare providers, much larger than the $2-8 \%$ 
reported in the general US population receiving medical care [23]. In a recent review by Siabani and colleagues, poor doctor-patient communication and a lack of faith in providers impeded patients' CHF-related help-seeking behavior and influenced medication beliefs [12]. Our themes of the importance of responsive, personalized care and the perception of providers as advocates support the centrality of the patient-provider relationship in facilitating patient engagement to improve CHF care. Though not rising to the level of a consistent theme at the semantic level, our data suggested a potential interplay between patient and provider characteristics and behaviors, in that many of our participants who described having a system advocate also acted as self-advocates and were highly engaged in their own care. Patient behavior may have inspired stronger advocacy from the provider, while the provider's advocacy may also have increased the patient's engagement.

Our participants' implicit definitions of access encompassed not just the narrow definition of quick physical access to an appointment but also emphasized the quality of communication with the care team, the ability of the care team to "match" the patient's sense of urgency, and a feeling of adequate time and attention during encounters. Our findings suggest that conventional measures of access (number of days until an open appointment) are an incomplete measure of what improved access would mean for CHF patients. A better performance measure would include both the timeliness of access and the intrinsic quality of encounters. Even though this study took place in the context of a significant organizational shift to a new teambased model of primary care, few patients explicitly identified this transition. However, our participants' emphases on the importance of good communication and of having an advocate have important implications for team-based care. Patients often described members of the primary care team other than the PCP as being their advocate or key point of contact. This aligns well theoretically with the PCMH model, where although the PCP is central to providing care, $s$ /he does not bear sole responsibility for patient communication and education. Our participants' comments suggest that many members of the care team can successfully fulfill this advocate role. It also shows that provider-patient communication in this setting extends beyond communication with the PCP. Participants identified good communication with other team members as an important contributor to effective selfcare. Successful care strategies for CHF may depend on identifying which team members are best able to serve as advocates and continuing points of contact for patients.

For many of our participants, the most important facilitator of CHF self-management was an engaged family member or supporter. Our study participants frequently described a high level of involvement of the supporter in self-care activities, which is in line with conclusions of prior studies [16,22,24]. An emerging literature explores the needs of informal caregivers for $\mathrm{CHF}$ patients and specific ways they help patients manage CHF $[25,26]$. Low levels of social support may be an important barrier to the implementation of self-management for CHF. Conversely, active inclusion of supporters in clinical encounters or educational activities may be a particularly effective way to improve selfmanagement.

A recent narrative review of CHF self-care concluded that depression is the most common comorbidity impeding ability to self-manage, surpassing physical co-morbidities (diabetes, asthma, and arthritis) [16]. Our study highlights gaps in the system's ability to address co-occurring physical and mental health issues, as very few participants had discussed with their providers strategies for how to decrease psychological barriers to engagement in self-care.

Our participants all received care in the VA system, and most conveyed a relatively solid understanding of $\mathrm{CHF}$, its underlying mechanisms, and knowledge of self-care activities. They tended not to identify challenges with cost of medication or access to medical services (in the sense of getting the "foot in the door"). This contrasts with findings of previous qualitative investigations $[12,17,27]$. Mead and colleagues discuss how cost and access to services interact with other barriers to deter self-management. However, our study provides evidence of the significant remaining barriers to self-care in an integrated, subsidized health care system that ameliorates certain cost, access, and knowledge-related barriers.

Some participants expressed frustration with access to specialty care. This frustration appeared driven by either the PCP's admission of a lack of expertise in managing CHF, and/or the patient's expectation that CHF should be managed by a cardiologist. In the $\mathrm{PCMH}$, most routine clinical care for $\mathrm{CHF}$ will occur in primary care settings. In the VA and other health care systems adopting the $\mathrm{PCMH}$, it may be useful to discuss explicitly with patients and supporters the respective roles and uses of primary care and specialty teams in the medical home model [28].

Our study had several limitations. Our participants were predominantly white, males receiving care in the VA healthcare system. A few patients expressed extreme satisfaction or dissatisfaction with care, which may be the result of self-selection bias that skewed results toward more extreme patient experiences.

\subsection{Conclusion}

This set of patient interviews found that patients with CHF place a strong emphasis on their relationships with healthcare providers and personal supporters for carrying out self-care activities. The participants valued the ability to have an individual health professional who provided advocacy and coordination of their care. Some participants identified primary care team members other than the PCP as playing a key continuity role in managing CHF. For many patients, responsibility for daily tasks associated with CHF self-care, such as medication adherence and management, were assumed by a supporter rather than the patient. Patients also felt that co-existing mental health problems affected their CHF care, yet these concerns were often unaddressed in their interactions with the healthcare system.

\subsection{Practice implications}

Our study generated new insights into the experiences and priorities of patients with CHF. Our findings have several important implications for health systems transforming to the medical home model. Programs to increase patient self-management should include attention to communication between patients and members of the primary care team. Care team members can provide important support via a continuity relationship and explicit advocacy efforts on behalf of patients. Considering the critical role many supporters play in managing patients' care, effective CHF care plans should explicitly acknowledge and accommodate the role of these supporters.

\section{Conflicts of interest}

The authors report no conflicts of interest, financial or otherwise, related to the content of this paper.

I confirm all patient/personal identifiers have been removed or disguised so the patient/person(s) described are not identifiable and cannot be identified through the details of the story.

This manuscript was written in the course of employment by the United States Government and it is not subject to copyright in the United States. 


\section{Acknowledgements}

We thank the Veterans, their family members, and close friends for sharing their experiences, and gratefully acknowledge the contribution of all members of the VISN 20 PACT Demonstration Lab. Funding for the PACT Demonstration Laboratory initiative is provided by the VA Office of Patient Care.

\section{Appendix A. Interview guide}

I. Congestive Health Failure

a Tell me a little bit about your CHF.

i How does it affect your life?

ii What types of symptoms do you have?

iii What's it like having CHF?

iv How have you handled having CHF?

II. Healthcare Interactions

I would like to know a little bit about the healthcare you have been getting for your CHF.

- Where do you get healthcare for your CHF? (get name of clinic(s) to use in discussion)

- Who takes care of your CHF? (get name of PCP or other providers who are involved in care; clarify who they are)

- Are there other team members, like nurses or assistants that help you or your doctor take care of your CHF? (get names and clarify who they are)

a Overall, what do you think about the healthcare you are getting for your CHF?

i. What do you like about it? What is going well?

ii. What don't you like about it?

iii. Have there been any problems?

iv. What do your healthcare providers do that you find useful?

v. What would you like them to do differently?

b We are interested in learning more about how teams of healthcare workers - like nurses or medical assistants - can work together with your doctor to help take care of your CHF. Tell me a little about your interactions with the people who work with your doctor in the primary care clinic.

i. Have they been helpful?

ii. Do you like working with other team members?

iii. What was good or bad about that?

iv. What can they do differently?

c Healthcare providers sometimes help patients try to do things themselves to take better care of their CHF. Has anyone at the $<$ clinic $>$ talked to you about what you can do for your CHF? Tell me about that.

i What types of things have they told you to do?

ii How does $<$ name $>$ or the other team members teach you about $\mathrm{CHF}$ ?

iii Does anyone check in with you about your CHF?

iv What has been helpful? Why?

$v$ Have you been able to do what $<$ name $>$ has suggested? vi Have you found this useful?

vii Is there anything that they could do differently to help you take care of your CHF?

III. Self-Management

We've talked a lot about the care you get for your CHF from your healthcare providers, and some of the things that they have told you to do. Now, I'd like to talk a little bit more about the things you are actually doing on your own to take care of your $\mathrm{CHF}$ a. What do you do to manage or take care of your CHF?

(Pause to see how patient responds. Ok to mix order of questions below as needed. For each one, explore:

i Has that been helpful? Why or why not?

ii What has made it easier or harder to do that?

iii What would make that easier/more helpful/less frustrating?)

b. What types of things do you to keep track of your symptoms - for example, do you do anything to keep track of your shortness of breath, your weight, how swollen your legs get, or other such things?

c. What do you do to keep track of your medications or to make sure you are taking them like you are supposed to?

$\mathrm{d}$. What types of changes, if any, have you tried to make to your diet or exercise because of your CHF?

e. What other things are you doing to help manage your CHF? For example,

f. (If hasn't already come out in discussion) Do you feel like the things that you do actually make a difference?

IV. Patient Education

a. How and where have you learned about CHF?

i. What was most useful? Why?

ii. Where do you get information that you can trust?

iii. How have you used what you learned?

b. What else would you like to learn about CHF?

c. What would be the best way to learn more about CHF?

V. Support Network

(If patient has mentioned supporters) You've mentioned your __ spouse/family member/caregiver. I would like to talk a little bit about how he/she/they support you.

(If patient has not mentioned any supporters) Does anyone help you manage your CHF? (If not, explore a little as to why and if they need/want support and then skip to next section)

a. What kinds of things does/do do to help you take care of your CHF?

i. Has that been helpful? Why or why not?

ii. What else would you like help with?

VI. Hospital transitions

Now we're going to move into a slightly different section of the interview. Think about the last time you were in the hospital for your CHF. These questions are about what happened either while you were getting ready to leave the hospital or soon after you went home.

a. Before you left the hospital, what types of things did your doctors or other hospital staff discuss with you about your CHF?

i. Did anyone talk to you about how to take your medications and what they are for?

ii. What did they tell you about things you can do for your CHF at home?

iii. Did anyone talk with you about what support you may need at home?

iv. Did anyone talk to you about how and when you should get follow-up care?

(Further explore their answers with probes such as:

- Who discussed that with you?

- What kinds of things did they say?

- How helpful was that? Why?

- What would have made it more helpful?)

b. When you left the hospital, did you feel you knew what to do?

i. If no - what was confusing or unclear for you?

ii. If yes - what helped you to feel confident that you knew what to do? 
c. In the first week after leaving the hospital, did anyone contact you?

i (If yes, explore enough details to know what happened, then) How helpful was that? Why?

ii (If no) Would it have helped if someone from the hospital or clinic had called to check in on you right after you left the hospital?

d. What clinics did you go to within the first 4 weeks of leaving the hospital?

i. How did those visits go?

ii. Is there anything that would have made it easier to transition from your hospital stay back to your outpatient clinic(s)?

e. Did a nurse or other health care provider visit you at home?

i. (If yes, explore enough details to know what happened, then) How helpful was that? Why?

ii. (If no) Would it have helped if someone came to your house after you were discharged?

f. What else could have been done to make your transition from the hospital to home easier for you? How would that have helped?

VII. Wrap up:

We have talked a lot about your CHF today. Is there anything else that you would like me or the rest of the research team to understand about your CHF or the care that you get at the VA?

Thank you very much for your time. I really appreciated hearing about your experiences.

\section{References}

[1] Medicare Payment Advisory Commission A Data Book: Healthcare Spending and the Medicare Program. Washington, D.C: Medicare Payment Advisory Commission; 2009

[2] American heart association statistics committee and stroke statistics subcommittee. heart disease and stroke statistics - 2008 update: a report from the american heart association statistics committee and stroke statistics subcommittee. Circulation 2008;117:e25-146.

[3] Lorig KR, Holman H. Self-management education: history, definition, outcomes, and mechanisms. Ann Behav Med 2003;26:1-7.

[4] Lainscak M, Blue L, Clark AL, Dahlström U, Dickstein K, Ekman I, et al. Self-care management of heart failure: practical recommendations from the Patien Care Committee of the Heart Failure Association of the European Society of Cardiology. Eur J Heart Fail 2011;13:115-26.

[5] DeBusk RF, Miller NH, Parker KM, Bandura A, Kraemer HC, Cher DJ, et al. Care management for low-risk patients with heart failure: a randomized, controlled trial. Ann Intern Med 2004;141:606-13.

[6] Jaarsma T, van der Wal MH, Lesman-Leegte I, Luttik ML, Hogenhuis J, Veeger NJ et al. Effect of moderate or intensive disease management program on outcome in patients with heart failure: Coordinating Study Evaluating Outcomes of Advising and Counselling in Heart Failure ( $\mathrm{COACH})$. Arch Intern Med 2008;168:316-24.
[7] Kasper EK, Gerstenblith G, Hefter G, Van Anden E, Brinker JA, Thiemann DR, et al A randomized trial of the efficacy of multidisciplinary care in heart failure outpatients at high risk of hospital readmission. J Am Coll Cardiol 2002;39:471-80.

[8] Farrell K, Wicks MN, Martin JC. Chronic disease self-management improved with enhanced self-efficacy. Clin Nurs Res 2004;13:298-308.

[9] Smeulders ESTF, van Haastregt JCM, Ambergen T, Uszko-Lencer NHKM, Janssen-Boyne JJJ, Gorgels APM, et al. Nurse-led self-management group programme for patients with congestive heart failure: randomized control trial. J Adv Nurs 2010;66:1487-99.

[10] Powell LH, Calvin JE, Richardson D, Janssen I, de Leon CFM, Flynn KJ, et al. Selfmanagement counseling in patients with heart failure the heart failure adherence and retention randomized behavioral trial. J Amer Med Assoc 2010;304:1331-8

[11] Wagner EH, Coleman K, Reid RJ, Phillips K, Sugarman JR.In: Guiding Transformation: How Medical Practices Can Become Patient-Centered Medical Homes. The Commonwealth Fund; 2012.

[12] Siabani S, Leeder SR, Davidson PM. Barriers and facilitators to self-care in chronic heart failure: a meta-synthesis of qualitative studies. Springer Plus $2013 ; 2: 320$.

[13] Thornhill K, Lyons AC, Nouwen A, Lip GYH. Experiences of living with congestive heart failure: a qualitative study. Brit J Health Psych 2008:13:155-75.

[14] Yu DSF, Lee DTF, Kwong ANT, Thompson DR, Woo J. Living with chronic heart failure: a review of qualitative studies of older people. J Adv Nurs 2008;61:474-83.

[15] Horowitz CR, Rein SB, Leventhal H. A story of maladies, misconceptions and mishaps: effective management of heart failure. Soc Sci \& Med 2004;58: 631-43.

[16] Jeon Y, Kraus SG, Jowsey T, Glasgow NJ. The experience of living with chronic heart failure: a narrative review of qualitative studies. BMC Health Serv Res 2010;10:77.

[17] Mead H, Andres E, Ramos C, Siegel B, Regenstein M. Barriers to effective selfmanagement in cardiac patients: the patient's experience. Patient Educ Couns 2010;79:69-76.

[18] Patient Centered Primary Care Implementation Work Group, VHA Patient Centered Medical Home Model (PACT) concept paper, 2011

[19] Braun V, Clarke V. Using thematic analysis in psychology. Qual Res Psychol 2006;3:77-101.

[20] Hsieh HF, Shannon SE. Three approaches to qualitative content analysis. Qual Health Res 2005;15:1277-88.

[21] Riegel B, Carlson B. Facilitators and barriers to heart failure self-care. Patient Educ Couns 2002;46:287-95.

[22] Welstand J, Carson A, Rutherford P. Living with heart failure: an integrative review. Int J Nurs Stud 2009;46:1374-85.

[23] Zickmund SL, Blasiole JA, Brase V, Arnold RM. Congestive heart failure patients report conflict with their physicians. J Card Fail 2006;12:546-53.

[24] Granger BB, Sandelowski M, Tahshjain H, Swedberg K, Ekman I. A qualitative descriptive study of the work adherence to a chronic heart failure regimen: patient and physician perspectives. J Cardiovasc Nurs 2009;24: $308-15$.

[25] Kang X, Li Z, Nolan MT. Informal caregivers' experiences of caring for patients with chronic heart failure systematic review and metasynthesis of qualitative studies. J Cardiovasc Nurs 2011;26:386-94.

[26] Malloy GJ, Johnston DW, Witham MD. Family care giving and congestive heart failure: review and analysis. Eur J Heart Fail 2005;7:592-603.

[27] Falk H, Ekman I, Anderson R, Fu M, Granger B. Older patients' experiences of heart failure-an integrative literature review. J Nurs Scholarship 2013;45: 247-55.

[28] Pharmacy Benefits Management Strategic Healthcare Group and Medical Advisory Panel, PBM-MAP Clinical Practice Guideline for the Pharmacologic Management of Chronic Heart Failure in Primary Care Practice Veterans Health Administration Department of Veterans Affairs, 2007; [Publication No. 00-0015] 